\title{
ACRYLIC CEMENT CREEPS BUT DOES NOT ALLOW MUCH SUBSIDENCE OF FEMORAL STEMS
}

\author{
N. VERDONSCHOT, R. HUISKES \\ From the University of Nijmegen, The Netherlands
}

It has been suggested that the endurance of cemented femoral reconstructions in total hip arthroplasty is affected by the creep of acrylic cement, but it is not known to what extent cement creeps under loading conditions in vivo, or how this affects load transfer. We have simulated the long-term creep properties of acrylic cement in finite-element models of femoral stem constructs and analysed their effects. We investigated whether subsidence rates measured in vivo could be explained by creep of acrylic cement, and if polished, unbonded, stems accommodated creep better than bonded stems.

Our findings showed that polished prostheses subsided only about $50 \mu \mathrm{m}$ as a result of cement creep. The long-term prosthetic subsidence rates caused by creep of acrylic cement are therefore very small and do not explain the excessive migration rates which have sometimes been reported. Cement creep did, however, relax cement stresses and create a more favourable stress distribution at the interfaces. These trends were found around both the bonded and unbonded stems. Our results did not confirm that polished, unbonded, stems accommodated creep better than bonded stems in terms of cement and interface stress patterns.

J Bone Joint Surg [Br] 1997;79-B:665-9.

Received 16 August 1996; Accepted after revision 21 March 1997

Retrieval studies ${ }^{1}$ and stress analyses ${ }^{2}$ have indicated that the fatigue strength of acrylic bone cement is inadequate to prevent fatigue fracture, particularly when the cement-stem interface debonds in part. Cement fractures are often associated with prosthetic subsidence. Plastic materials, such as acrylic cement, gradually deform when they are exposed to long-term loading, a phenomenon known as creep. It has been suggested that creep of acrylic cement allows the

N. Verdonschot, PhD, Director of Joint Replacement Biomechanics R. Huiskes, PhD, Professor

Biomechanics Section, Institute of Orthopaedics, University of Nijmegen, PO Box 9101, 6500 HB Nijmegen, The Netherlands.

Correspondence should be sent to Dr N. Verdonschot.

C 1997 British Editorial Society of Bone and Joint Surgery 0301-620X/97/47173\$2.00 expansion of the cement mantle and subsequent prosthetic subsidence without causing cement fractures. According to Fowler et al, ${ }^{3}$ prosthetic components should have tapered shapes and polished surface finishes to accommodate optimally the effects of creep.

Another time-dependent property of acrylic cement, which is closely related to creep, is the gradual reduction of stress after the material has been stretched to a constant level. This is known as stress relaxation. Acrylic cement has been identified as having a high stress-relaxing potential, implying that cement stresses may reduce considerably with time, thereby extending the mechanical endurance of a hip reconstruction. ${ }^{4}$ The time-dependent deformation process of acrylic cement results in both creep and stress relaxation. It is certain that acrylic cement creeps, ${ }^{5-7}$ but to what extent this process is clinically important is not known.

Our aim was to determine the effects of creep in acrylic cement on the mechanical behaviour of femoral stem constructs. For this purpose we applied a method to simulate the creep process of bone cement which had been validated in an earlier study, ${ }^{8}$ to three-dimensional finite-element models of femoral stem constructs.

\section{MATERIALS AND METHODS}

We used CT to scan an embalmed femur and created a finite-element model from the geometrical contours and densities of the CT data. We then created a finite-element model of an Exeter stem which was introduced into the bone model. The cement mantle had a minimum thickness of $2 \mathrm{~mm}$. Distal to the stem tip there was no cement, simulating a space created by a centraliser. The model contained 2130 8-node isoparametric elements and 3360 nodal points (Fig. 1). The cement-stem interface was assumed to be completely bonded (simulating a surface with a high surface roughness) or completely unbonded (simulating a highly polished prosthetic surface). In the latter case, a friction coefficient of 0.25 was assumed ${ }^{8,9}$ and special gap elements (MARC Analysis Research Corporation, Palo Alto, California) were used to simulate the nonlinear contact mechanics between the polished metal surface and the cement mantle.

For the bone elements, the formula of Carter and Hayes ${ }^{10}$ was used to transfer the bone densities obtained by 


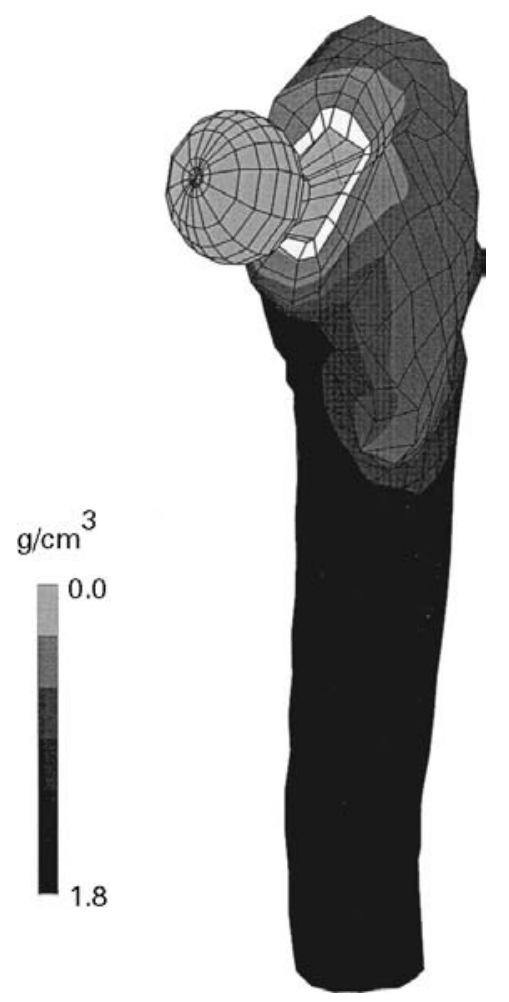

Fig. 1

The three-dimensional CT-based anatomical finite-element model used in the analyses. The density distribution $\left(\mathrm{g} / \mathrm{cm}^{3}\right)$ of the bone is shown.

CT to elastic moduli. The elastic modulus for the cement material was set to $2.2 \mathrm{GPa}^{11}$ and Poisson's ratio to 0.3 . The creep properties of acrylic cement had been determined in earlier studies ${ }^{5-7}$ and implemented as described by Verdonschot and Huiskes. ${ }^{8}$ The elastic modulus and Poisson's ratio for the prosthetic material were $200 \mathrm{GPa}$ and 0.28 , respectively, simulating stainless-steel prosthetic material.

One loading case was considered to be presented by the stance phases of the gait cycle. This consisted of a load of $2450 \mathrm{~N}$ acting on the prosthetic head with angles of $23^{\circ}$ in the frontal and about $6^{\circ}$ in the sagittal plane. ${ }^{12}$ In addition, three muscle forces (gluteus minimus, medius and maximus) were also represented, acting on the greater trochanter. The resultant of these three muscle forces was about $1650 \mathrm{~N}$, with angles of $24^{\circ}$ in the frontal and $15^{\circ}$ (directed anteriorly) in the sagittal plane. ${ }^{13,14}$

The possible consequences of cement creep on the probability of failure of the cement mantle was deduced by considering the maximal and the average stress values in the cement mantle as a function of postoperative time. The effects of creep on load transfer at the interfaces were analysed by integrating the stresses over the interface surface. This resulted in the total shear, tensile and compressive forces being transferred at the interfaces.

The subsidence of the unbonded stem within the cement mantle was analysed by considering the gap created between the proximolateral stem surface and the cement mantle, as can also be estimated from radiographs in clinical practice. ${ }^{3}$

\section{RESULTS}

Around both the bonded and unbonded stems, creep reduced tensile stresses in the cement, predominantly in the external periphery of the cement mantle, whereas stress peaks around the corners of the stems were maintained. Initially, the bonded stem generated maximal tensile stresses at the lateral, exterior side of the cement mantle, which gradually relaxed due to creep of the cement (Fig. 2a). At the same time, however, the bonded stem developed higher cement stresses near the cement-stem interface, particularly at the proximal side (Fig. 2b). For this reason, the peak stress value generated around the bonded stem first reduced slightly, and then increased somewhat after 10000 loading cycles (Fig. 3a). Around the unbonded stem, the highly stressed locations did not change during the creep process, resulting in a slight increase in tensile peak stress as the stem gradually subsided in the cement mantle (Fig. 2). Although the stress peaks around both stems changed only moderately, the effect of creep on the average value of the tensile stresses was substantial. Around both types of stem the average tensile stress value decreased by about $50 \%$ (Fig. 3b).

The stresses at the bonded cement-stem interface developed favourably due to creep (Fig. 4). The total shear force transmitted at the interface decreased by about $20 \%$ after 5 million loading cycles, whereas the tensile and compressive forces remained more or less constant. Around the unbonded stem, shear forces were lower and compressive forces higher as compared with the bonded stem. Due to creep, compressive and shear forces were increased by almost $50 \%$ after 5 million loading cycles (Fig. 4). Tensile forces at the cement-stem interface were absent due to the fact that the polished surface did not adhere to the cement mantle.

Around the bonded stem, the shear forces decreased and compressive forces increased at the cement-bone interface after creep had occurred (Fig. 5). The tensile forces remained at a constant level and were much lower (by a factor of three) when the prosthesis was assumed to be unbonded and decreased slightly due to creep. Shear forces were comparable to those generated by a bonded stem and were hardly affected by cement creep. The high compressive forces at the cement-stem interface created around the unbonded stem were transmitted to the cement-bone interface, resulting in relatively high compressive force values. They increased considerably due to creep of the cement (Fig. 5).

Although creep allowed the unbonded prosthesis to subside within the cement mantle, the actual amount of subsidence was relatively small. Immediately after the first load application, the unbonded prosthesis was forced into the cement mantle and a gap of about $25 \mu \mathrm{m}$ was created (Fig. 
Bonded

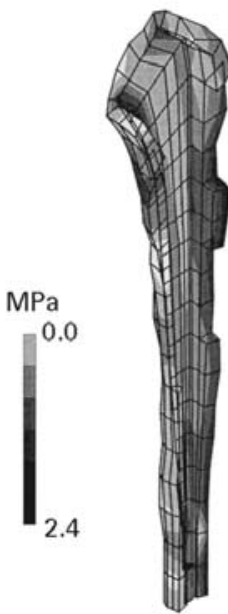

Pre

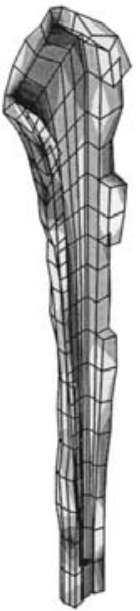

Post

Unbonded
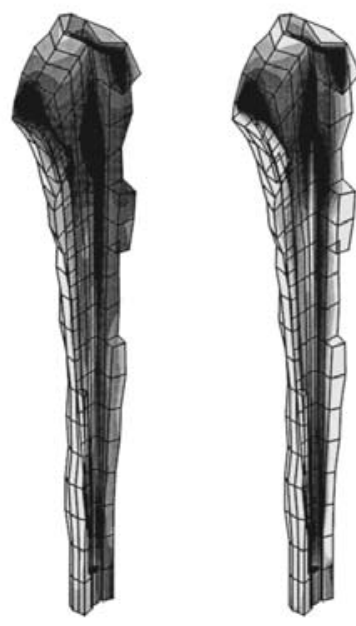

Pre Post creep

Fig. 2a

Bonded

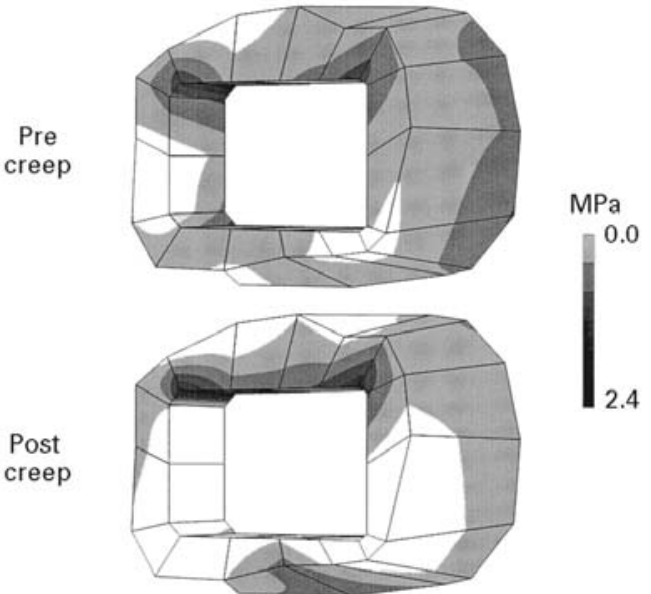

Unbonded
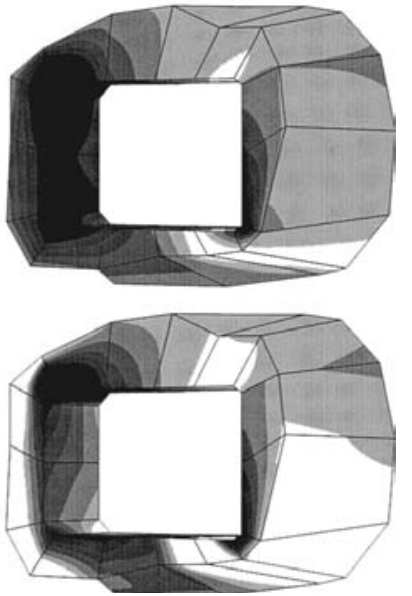

Fig. 2b

Posteromedial (a) and resection level (b) views of the tensile stress distribution in the cement mantle at the pre- and postcreep stage.

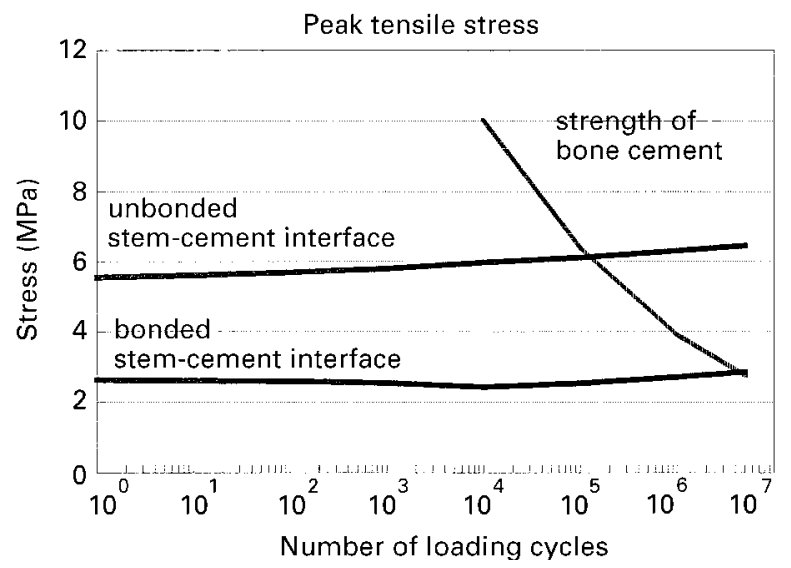

Fig. 3a

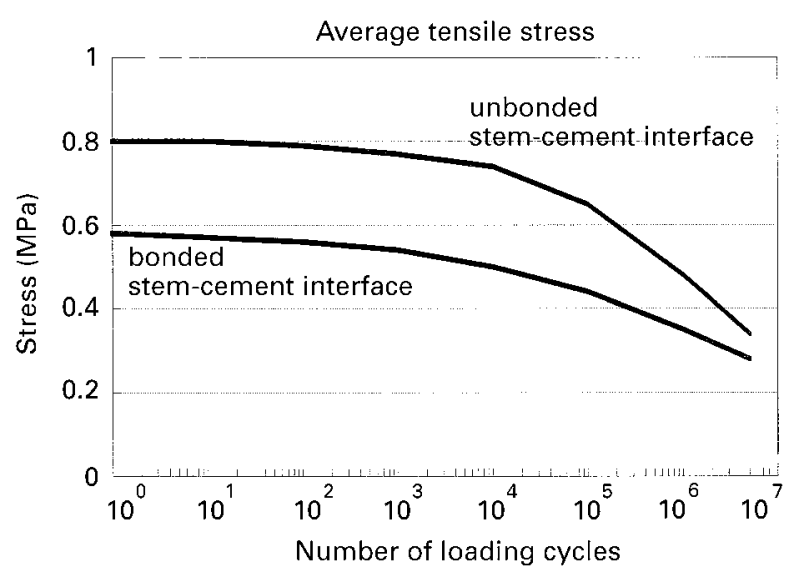

Fig. 3b

Figure $3 \mathrm{a}$ - The peak tensile stress in the cement mantle remained rather constant and approached the fatigue strength of the bone cement $\left(\right.$ Davies et al ${ }^{18}$ ) after 100000 loading cycles in the case of unbonded cement-stem interface conditions, and after 5 million loading cycles with bonded cement-stem interfaces. Figure $3 b$ - The average tensile stress generated in the cement mantle decreased around both types of stem as the creep process proceeded. 


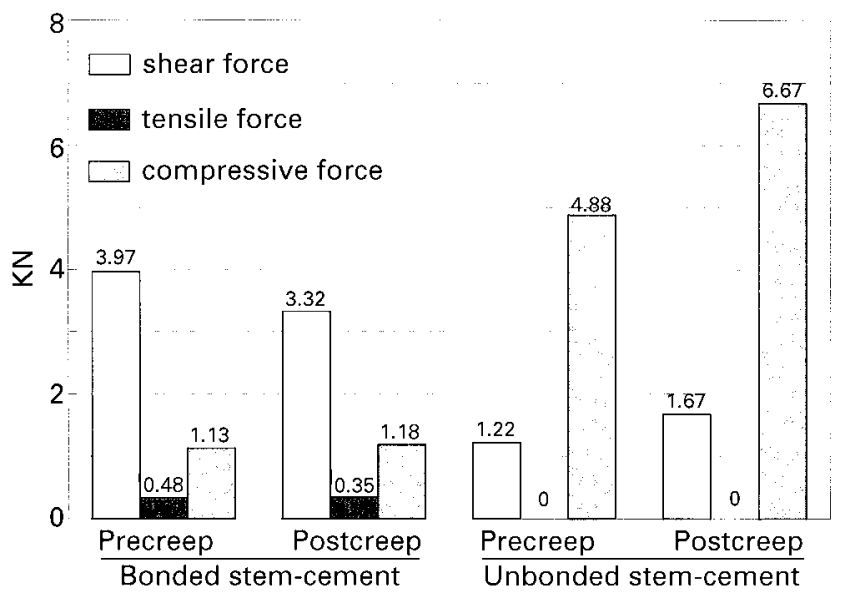

Fig. 4

The total shear, compressive, and tensile forces distributed at the cementstem interface.

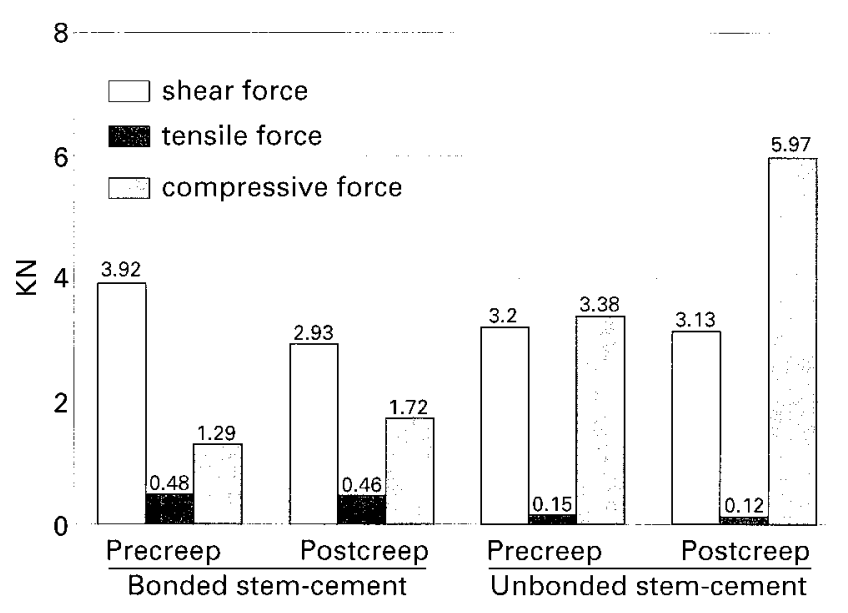

Fig. 5

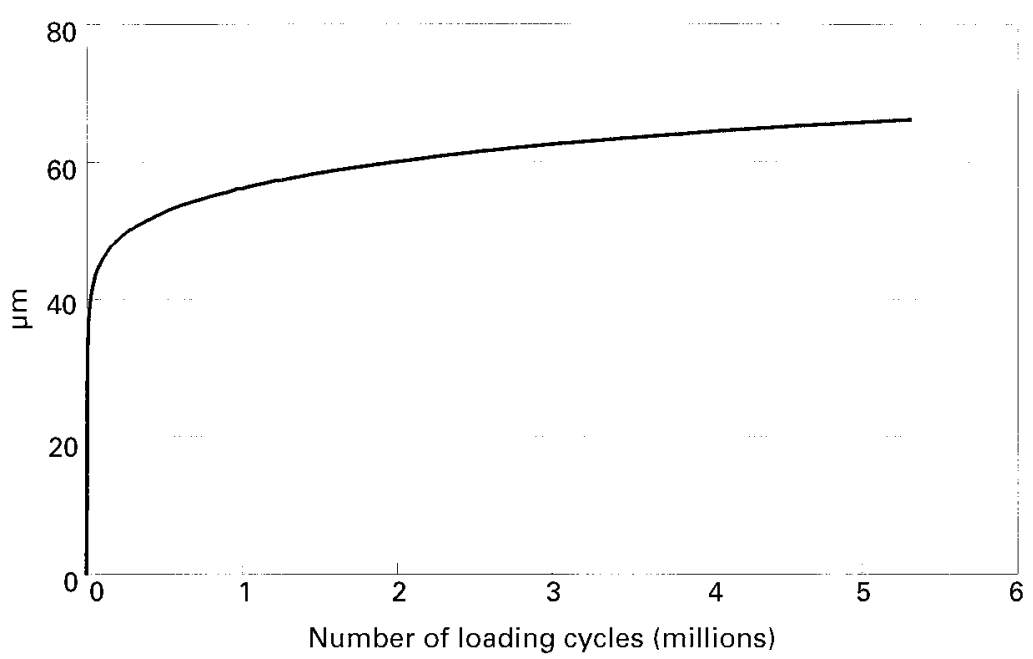

Fig. 6

Directly after the first load application, the unbonded prosthesis was forced into the cement mantle and a gap of about $25 \mu \mathrm{m}$ was created. As the cement material was allowed to creep, the stem subsided gradually but marginally in the cement mantle.

6). While the cement material crept, the stem subsided gradually in the cement mantle, but the subsidence rate decreased rapidly after the first 250000 loading cycles. After 5 million loading cycles the gap size was about $65 \mu \mathrm{m}$.

\section{DISCUSSION}

The finite-element model used in our study is based on a number of assumptions which should be appreciated when the results are assessed. We used only one particular design of stem without any collars and assumed an ideal implantation with an intact cement mantle. We also assumed that bone properties were constant during the 5 million loading cycles, whereas it is known that bone is subject to continuous remodelling and changes in density and therefore in its mechanical properties after placement of a femoral implant. ${ }^{15}$ Only one loading case was considered, simulating the midstance phase of gait. Although this is the loading case most frequently applied to the reconstruction, others, such as those generated during stair-climbing, were not included in the study. In addition, the 5 million loading cycles were assumed to have been applied continuously; normally, patients have alternating periods of activity and rest. During the latter the stresses are allowed to relax to some extent, thereby reducing the constraining capacity of the cement mantle against subsidence. The stem may therefore subside somewhat when the patient becomes active again after a period of rest. The size of these subsidence steps, however, is likely to reduce in time. The reason for this is that the amount of creep depends, apart from the stress level, also on the creep history. With an increasing number of active and resting periods, the total creep strain increases and therefore reduces the creep strain rate which leads to a gradual reduction of the amount of prosthetic subsidence after subsequent resting periods. The size of this subsidence step is unknown but based on the present information it can be expected to be very small. In our present study, however, the resting periods were not included.

Lee et $\mathrm{al}^{4}$ have shown that the dynamic creep rate of acrylic cement is sensitive to the age of the cement. In a dynamic four-point bending test they found a twofold increase in creep rate with seven-day-old specimens as 
compared with 42-day-old specimens. The creep properties of acrylic cement used in our study had been determined in earlier studies, ${ }^{5-7}$ in the last two of which the acrylic cement had been tested one month after mixing. Hence, the simulation did not include the early period and may underestimate the subsidence rate at that stage.

Fowler et al, ${ }^{3}$ determined the clinical migration rates by measuring the gap between the proximal cement and the surface of Exeter femoral components from standard anteroposterior radiographs. They found subsidence of more than $1 \mathrm{~mm}$ after five to ten years postoperatively in $36 \%$ of all cases, which increased to $65 \%$ five years later. They hypothesised that these subsidence patterns could be explained by the creep capacity of cement. Our findings suggest, however, that the effects of creep on the stem migration patterns are very small. In the model the maximum long-term migration was subsidence of about $65 \mu \mathrm{m}$ in the unbonded stem. Hence, we found that cement creep accounts for less than $10 \%$ of the subsidence values measured clinically and it is therefore unlikely that the subsidence visible on radiographs is caused by creep. The causes of the subsidence reported remain uncertain. Fowler et $\mathrm{al}^{3}$ analysed components which had been implanted with so-called first-generation cementing techniques. ${ }^{16}$ It is possible that these techniques resulted in porous or incomplete cement mantles, which may have contributed to the subsidence patterns of the components. In addition, subsidence may be promoted by cement-stem interfacial porosity which can be as much as $50 \%$, even when advanced mixing procedures are used. ${ }^{17}$ Obviously, cement cracks may allow substantial subsidence.

The effects of creep on the cement stresses were analysed by considering the maximal and average cement stress values. For both the bonded and unbonded stems creep of the cement did not reduce the maximal stress values but the average values decreased by about $50 \%$. Creep of acrylic cement may not therefore prevent cement cracking, but certainly decelerates the failure process in the cement mantle.

In general, creep had a positive effect on the interface stress patterns. At the bonded cement-stem interface, the total shear force decreased, whereas the compressive stresses increased. Both of these trends led to a reduction of the probability of stem-cement debonding. At the cement-bone interface, the unbonded stem produced stress patterns which were more favourable than those generated by the bonded stem. In the former, higher compressive stresses and lower tensile stresses were produced. Cement creep reduced the probability of failure at this interface by reducing the shear stresses and elevating the compressive stresses of the bonded stem, and by increasing the compressive stresses around the unbonded stem.

Our study did not confirm that polished stems accommodate creep better than bonded stems, as hypothesised by Fowler et al. ${ }^{3}$ The probability of cement-bone interface failure was consistently lower in unbonded, polished stems and was further reduced by cement creep. A polished stem can therefore be considered to be advantageous. Nevertheless, the probability of cement-stem debonding, which has been considered as a potential negative asset of stems that firmly bond to their cement mantles, ${ }^{3}$ was reduced by cement creep. The probability of cement failure was lower in bonded compared with unbonded, polished stems and was not changed by creep.

Our study has shown that creep of acrylic cement results in relaxation of cement stresses and decelerates the failure process in the cement mantle. Prosthetic subsidence rates caused by creep of acrylic cement are very small and do not explain the excessive migration rates which have been reported.

Although none of the authors have received or will receive benefits for personal or professional use from a commercial party related directly or indirectly to the subject of this article, benefits have been or will be received but are directed solely to a research fund, educational institution, or other non-profit institution with which one or more of the authors is associated.

\section{REFERENCES}

1. Jasty M, Maloney WJ, Bragdon CR, et al. The initiation of failure in cemented femoral components of hip arthroplasties. $J$ Bone Joint Surg [Br] 1991;73-B:551-8.

2. Huiskes R. Mechanical failure in total hip arthroplasty with cement. Curr Orthop 1993; 7:239-47.

3. Fowler JL, Gie GA, Lee AJ, Ling RS. Experience with the Exeter total hip replacement since 1970. Orthop Clin North Am 1988;19: 477-89.

4. Lee AJC, Perkins RD, Ling RSM. Time-dependent properties of polymethylmethacrylate bone cement. In: Older J, ed. Implant bone interface. London etc: Springer-Verlag, 1990:85-90.

5. Chwirut DJ. Long-term compressive creep deformation and damage in acrylic bone cements. J Biomed Mater Res 1984;18:25-37.

6. Verdonschot N, Huiskes R. Creep behaviour of hand-mixed Simplex $\mathrm{P}$ bone cement under cyclic tensile loading. J Appl Biomat 1994;5: 235-43.

7. Verdonschot N, Huiskes R. Dynamic creep behaviour of acrylic bone cement. J Biomed Mater Res 1995;29:575-81.

8. Verdonschot N, Huiskes R. Subsidence of THA stems due to acrylic cement creep is extremely sensitive to interface friction. J Biomech $1996 ; 29: 1569-75$.

9. Mann KA, Bartel DL, Wright TM, Burstein AH. Coulomb frictional interfaces in modeling cemented total hip replacements: a more realistic model. J Biomech 1995;28:1067-78.

10. Carter DR, Hayes WC. The behaviour of bone as a two-phase porous structure. J Bone Joint Surg [Am] 1977;59-A:954-62.

11. Saha S, Pal S. Mechanical properties of bone cement: a review. J Biomed Mater Res 1984;18:435-62.

12. Bergmann G, Graichen F, Rohlman A. Hip joint loading during walking and running, measured in two patients. J Biomech 1993;26: 969-90.

13. Crowninshield RD, Brand RA. A physiologically based criterion of muscle force prediction in locomotion. J Biomech 1981;14:793-801.

14. Dostal WF, Andrews JG. A three-dimensional biomechanical model of hip musculature. J Biomech 1981;14:803-12.

15. Engh CA, McGovern TF, Schmidt LM. Roentgenographic densitometry of bone adjacent to a femoral prosthesis. Clin Orthop 1993; 292:177-90.

16. Harris WH. Is it advantageous to strengthen the cement-metal interface and use a collar for cemented femoral components of total hip replacements. Clin Orthop 1992;285:67-72.

17. James SP, Schmalzried TP, McGarry FJ, Harris WH. Extensive porosity at the cement-femoral prosthesis interface: a preliminary study. J Biomed Mater Res 1993;27:71-8.

18. Davies JP, Burke DW, O'Connor DO, Harris WH. Comparison of the fatigue characteristics of centrifuged and uncentrifuged Simplex P bone cement. J Orthop Res 1987;5:366-71. 